\title{
Grillz and Gold Teeth - Esthetic, Economics and Ethics
}

SADJ September 2021, Vol. 76 No. 8 p498 - p500

TM Mtolo', PD Motloba ${ }^{2}$

Case report: Anecdote from dental technician My laboratory has been providing services to a modest number of dental professionals for a while now. As part of prosthodontic work I have done, one has witnessed a generalised upsurge, albeit steady, in the request for gold inlays, followed by silver and grills overtime. The demand for these services is correlated with the location, period and ethos of the practice. Our practice has seen a drastic tapering down of requests during the Covid -19 period. Ultimately, there is a discernable driver for the demand of these services. We have also observed from dental casts that, the dentition appeared to be without any noticeable pathology. This implies that most patients requiring these prosthesis, have "virgin" teeth prepared.

Being a small laboratory, our numbers, are insignificant compared to bigger laboratories. Additionally, unregistered laboratories and jewellers have entered this space and are providing 'affordable' alternatives. On a typical month, our laboratory fabricates a total of 320 prosthesis of which gold inlays, constitute about 60\%, silver, $30 \%$ and grills, $10 \%$. These numbers are an under-representation of the extent of this phenomenon and the potential 'subdued' and untapped market, especially during this fierce Covid -19 economic downturn.

We hypothesise that we are witnessing the tip of an iceberg, and that under the right conditions, this grills and gold teeth epidemic will go beyond the tipping point. Given the cultural, economic and other factors, more and more youth will sustain the demand for these services in perpetuity.

\section{Dental adornment - evolution}

Human interpretation and understanding of 'looks' has at best been controversial or emotive. The ugly truth is that looks are for some, everything; for some, looks are important but not everything. However this matter is diced, appearance have always mattered since time in memorial

\section{Author affiliations:}

1. Thembelihle M Mtolo: BTech (DT)(TUT), Senior Dental Technologist, Dental Laboratory, Sefako Makgatho Health Sciences University, South Africa.

2. Pagollang D Motloba: BDS (Medunsa), MPH (Epidemiology) (Tulane), Head, Department of Community Dentistry, School of Oral Health Sciences, Sefako Makgatho Health Sciences University. ORCID Number: 0000-0003-1379-7576

Corresponding author: Prof PD Motloba

Dept Community Dentistry SMU, Pretoria, South Africa.

Email: pagollang.motloba@smu.ac.za .

\section{Author contributions:}

1. Thembelihle M Mtolo: Primary author - $50 \%$

2. Pagollang D Motloba: Second author $-50 \%$ and continues throughout civilization. There is nothing vain about how one looks, or how one wants to presents themselves to the world. People have throughout history chosen to embellish, decorate and beautify themselves with personal adornments, in order to present the best version of themselves to the unforgiving world. Jewelry, cosmetics or makeup and associated items continue to be used for this purpose.

Nowadays dental health and appearance has found expressions from those who want to be seen and appreciated. The demand for elective aesthetic procedures, such as braces, teeth whitening, crowns, and bridges is on the rise. Dental adornment is not new, but represent a reimagining of old traditions spanning back many centuries. Modern grillz and 'quintessential' pirate gold teeth have appeared, disappeared and reappeared in bursts and spouts, as civilization evolved. This modern expression of dental 'aesthetics' embodies the insatiable human desire to change their appearance including modifying their teeth.

Resurgence of the Grillz and gold teeth - revolution Grillz are wearables that snap over the wearers teeth. Grills are made of gold, silver or other metals which are encrusted with jewels at the pleasures of the wearers ${ }^{1}$ Mouth bling was first recorded in $800 \mathrm{BC}-200 \mathrm{BC}$ among the Etruscans in Italy. Rich Etruscans women wore decorative gold teeth, or teeth carved out of ivory and reused teeth among a plethora of dental adornments. ${ }^{2}$ Mayans are known to have used well carved stones to prepare the labial surfaces of anterior teeth. ${ }^{3}$ Meticulous fillings and inlays or a combination were then placed on these teeth according to tribe and regions. These forms of dental mutilation were done of maxilla anterior teeth for religious as well as aesthetic reasons.

The 1980s saw a major resurgence of grills and gold inlays as symbols of wealth and status. Grills or bling represented a fresh and unique expression of the cutting-edge hiphop culture, much more than mere costume jewelry of the time. ${ }^{4,5}$ Recently, various artists have reinvigorated and garnered interests in grills. Nelly in his number one hit 'Grills' in 2005 and Kanye West's revelation of his diamond encrusted mandibular grill, in Ellen DeGeneres in 2010, catapulted the grills culture into hip pop spotlight. ${ }^{6}$ The popular singer Rihanna, also displayed her removable gold grills in 2011 for her "You Da One" music video. These adornments do not come cheap, for example Lil Wayne bejeweled smile cost him over \$150,000, and Birdman around \$500,000. ${ }^{7}$

Cosmetic dentistry has not only been the preserve of the rich and powerful. Vikings, the Scandinavian's most celebrated traders, explorers and warriors, took pride in their appearance and modified their teeth as a mark of achieve- 
ment among the warriors. ${ }^{8}$ Similarly gold teeth have been associated with the villain character of 'pirate's desire for wealth, greed, and ostentation. This portrayal of conspicuous wealth is more fiction than reality.

Cosmetic or Aesthetic Dentistry - Matter of semantics These days many people do not necessarily opt for grillz or gold teeth, but rather opt or 'cosmetic' or aesthetic dentistry' to improve their general dental appearance. These procedures are undertaken to restore stained, discolored, chipped teeth, malocclusion and many more dental problems. ${ }^{9}$ As 'smile makeover' procedures, these procedures are often times undertaken on healthy teeth, just for the recipient to feel good about themselves. ${ }^{10}$ Some clinicians have lamented the usurping of 'need-based' dentistry by the 'want-based' dentistry camouflaged as cosmetic or aesthetic dentistry. Whether this phenomenon is driven by culture or cash. ${ }^{11,12}$ Either way, the implications can have far-reaching consequences for the profession and population.

The terms cosmetic and aesthetic dentistry are used interchangeably, despite their critical differences and application. By definition, cosmetic dentistry refers to provision of dental decoration or adornments meant to make the patient present better, more beautiful, or more impressive. ${ }^{13}$ These procedures are mere top-ups or additions to the existing dentition. They are reversible, do not cause lasting change or damage to dentitions and supporting tissues, neither do they improve function.

Aesthetics dentistry, is a "branch of philosophy dealing with beauty", which is challenging to conceptualise and execute in dental practice. The goal of aesthetic dentistry is to give the patient a natural look, resulting in an improvised and seamless transformation, while maintaining functional integrity. Aesthetic dentistry, also referred to as biomimetic dentistry or biomimetic procedures, 'recreates nature at its finest' by offering undetectable transformation, aimed at making the patients better than well. The complexity of aesthetic dentistry requires cooperation and excellence of multidisciplinary team, and most critically, patient participation. A plethora of dental procedures are offered as part of aesthetic dentistry, for example, crown and bridgework, orthodontic treatment, implants, periodontal surgery and orthognathic surgery. Notwithstanding these differences, dentists continue to provide a myriad of elective procedures, attributable to increasing patient's requests. The central questions about aesthetic dentistry is whether the procedures confer beauty, excellence or desirable and for whom? Beauty is always in the eyes of the beholder, the patient, society of the clinician.

\section{Ethical Implications}

Professional codes of conduct, moral and ethical principles provide guidance for clinical decision making by practitioners. Arising therefrom, the clinician is obligated to (i) provide timely, appropriate and safe dental care to the patients (beneficence); (ii) refrain from causing unnecessary harm to patients (non-maleficence); (iii) involve and respect of patient's needs and expectation throughout the course of clinical care (autonomy). ${ }^{14-16}$ Ultimately, a virtuous clinician will provide dental treatment aimed at achieving (i) greatest 'happiness' for the patient, by maximising utility or benefit over harm ${ }^{17}$ and (ii), always consider patient's agency ${ }^{18}$. Failure to provide patient-centered, predictable, safe, appropriate care is a blatant violation of ethical code of conduct and patient-dentist relationship.

Bader and Shugars ${ }^{19}$ state, "An implicit, if not explicit, assumption accompanying any treatment is that the benefits of the treatment will, or at least are likely to, outweigh any negative consequences of the treatment...in short, that treatment is better than no treatment."

The provision of grillz and gold inlays by dentists raises serious and interesting questions about this routine and 'socially' acceptable procedure. The ethical and moral dilemma arise as questions about aesthetics, ethics and economic collide. Whether this intervention necessarily proffer beauty, or result in economic and clinical harm to the patient is a matter is fierce contestation. Grillz and gold inlays may cause harm to patients, and simultaneously benefits the patients, and demonstrate respect for patient's wishes and preferences. Several arguments provide the pros and cons about grillz and gold inlays.

Anecdotally, dentists who oppose the provision of grillz and gold inlays argue that these procedures are akin to over-servicing or over-treatment. The contention is that the treatment is unnecessary, inappropriate and likely to cause harm than good. Furthermore, this treatment can be likened to dental mutilation, in which non -pathological, "virgin" teeth are tempered with and sound tooth structure is removed unnecessarily. These exposes patients to unknown risks of 'treatment'. Furthermore, there is limited evidence or research on the clinical efficacy and need for grillz and anterior gold restorations. Therefore, undertaking, irreversible procedures, using the restorative materials with untested, unproven clinical efficacy in the anterior region is analogous to clinical experimentation. ${ }^{20}$

The dentist has a duty to manage harmful and unrealistic patient's expectations. The provision of grillz and gold teeth, could indicate the failure of the clinician to obtain informed consent, properly counsel the patient and manage their expectations. Clinicians can be accused of undue influence or paternalism in favour of treatments that confer financial gains than clinical benefit. The advancement of commercial interests over clinical outcomes or economics over ethics pose a serious threat to patient-dentists relationship. ${ }^{12}$

The demand and financial incentives has spurred jewelers and unlicensed vendors provide grills and gold teeth to the public without additional training that dentists possess. Proponents of grillz and gold teeth contend that dental professionals are best suited to service this market, failing which it will go deep underground. Understandably, qualified professionals are appurtenant to provide this service safely and with minimal harm. There is case to be made about the social and emotional utility of these prosthesis.

Grills or bling legitimizes one's social standing and confers social benefits. These personal adornments are portable wealth which could accentuates one's stature and position in the social pecking order. This trend will continue driven by hip hop culture and the need to belong. The dental professionals must confront this situation in order to minimise potential harm to patients. 


\section{CONCLUSION}

When faced with patients requiring dental enhancements like grillz or gold teeth, an encounter which occurs often in some communities in South Africa. The dentists must uphold and act in accordance to the principle of "primum non nocere" or first do no harm. In so doing the patient's desire for adornment will be secondary to well-being, even at the expense of patient's autonomy - justifiable paternalism. It is incumbent on dentists to consider undertaking those procedures with positive benefit risk ratio, and decline potentially harmful interventions. Dentists must desist from prioritizing personal economic gain over care and ethics. Any clinically unnecessary inappropriate treatment is over-servicing which is fraudulent larceny and constitutes unethical conduct and a breach of the profession code of conduct. It is incumbent on the profession to regulate and develop guidelines for the fabrication and placements of these prosthesis. The alternative will have grave consequences to the patients, as this phenomenon is here to stay. The financial incentives are too great for jewelers and vendors of these dental adornments to abdicate. At the clinical level, practioners must discourage wearing of grills and gold teeth. In cases where patients have these prosthesis, dentists must encourage patients with grills to engage in proper oral hygiene practices, use fluoride and reduce prolonged wear. The stakes have never been high, the economic impact of Covid-19, has heightened the tension between aesthetics, ethics and economic. It is hoped that this paper has succeeded in elucidating areas of tension and solutions in managing patients requiring grills and gold teeth.

\section{References}

1. Patil AG. Tooth jewellery: A simple way to add sparkle to your smile. Ind J Dent Adv 2010; 2(4):356-58.

2. Becker MJ. Etruscan Gold Appliances: Origins and Functions as Indicated by an Example from Orvieto, Italy, in the Danish National Museum. Dental Anthropology Journal 1994; 8(3):2-8.

3. Crabb C. History of dental implants. Dental Nursing 2006; 2(8):398-99.

4. Flower I, Rosa-Salas M. Say My Name: Nameplate Jewelry and the Politics of Taste. QED: A Journal in GLBTQ Worldmaking 2017; 4(3):109-26. doi: 10.14321/qed.4.3.0109

5. Wilbekin E. Great aspirations: Hip hop and fashion dress for excess and success. Fashion Theory: Routledge 2020:355-60

6. Roberts B. A brief history of bling: Hip-hop jewelry through the ages: Highsnobiety; 2021 [Available from: https://www. highsnobiety.com/p/hip-hop-jewelry/ accessed 27 June 2021 2021.

7. West C. Lil Wayne and Birdman Grillz 2012 [Available from: https://curtismwest.wordpress.com/2012/03/30/lil-wayneand-birdman-grillz/6 June 2021.

8. Arcini C. The Vikings bare their filed teeth. American Journal of Physical Anthropology 2005; 128(4):727-33.

9. Blatz $M$, Chiche $G$, Bahat $O$, et al. Evolution of aesthetic dentistry. JDR 2019; 98(12):1294-304.

10. Sarin S, Gilbert D, Asimakopoulou K. Why simple aesthetic dental treatment in general practice does not make all patients happy. BDJ 2014; 216(12):681-85.

11. Nash DA. A tension between two cultures... dentistry as a profession and dentistry as proprietary. J Dent Educ 1994; 58(4):301-6.
12. Simonsen R. Commerce vs care: Troubling trends in ethics of aesthetic dentistry. Dent Clinics of North America 2007; 51(2):281-7.

13. Kelleher M. Ethical issues, dilemmas and controversies in' cosmetic' or aesthetic dentistry. A personal opinion. BDJ 2012; 212(8):365-67.

14. Thomas MV, Straus SE. Evidence-based dentistry and the concept of harm. Dental Clinics of North America 2009; 53(1):23-32.

15. Beauchamp TL, Childress JF. Principles of biomedical ethics: Oxford University Press, USA 2001

16. Gillon R. Defending 'the four principles' approach to biomedical ethics. Journal of Medical Ethics 1995; 21(6):323-4. doi: 10.1136/jme.21.6.323

17. Gillon R. Utilitarianism. BMJ (Clinical Research ed) 1985; 290(6479):1411-3.doi: 10.1136/bmj.290.6479.1411

18. Wood A. Humanity as end in itself. Proceedings of the Eighth International Kant Congress 1995; 1(1):302-19

19. Bader J, Shugars D. Variation, treatment outcomes and practice guidelines in dental practice. J Dent Educ 1995; 59:61-95.

20. Hollowell WH, Childers NK. A new threat to adolescent oral health: the grill. Pediatric dentistry 2007; 29(4):320-22. 